\title{
Discursos de enfermeiras sobre morte e morrer: vontade ou verdade?
}

\author{
Nurses' speeches on death and to die: truth or will?
}

Discursos de enfermeras sobre la muerte y el morir: ¿Voluntad o verdad?

\author{
Karen Schein da Silva', Rubia Guimarães Ribeiro', Maria HenriQueta Luce Kruse' \\ 'Universidade Federal do Rio Grande do Sul. Departamento de Enfermagem, \\ Programa de Pós-Graduação em Enfermagem. Porto Alegre, RS
}

\section{RESUMO}

Propomos olhar para a morte e o morrer como uma construção social, histórica e cultural. Assim, nos aproximamos dos Estudos Culturais para conhecer discursos de enfermeiras sobre o tema. O corpus da pesquisa são artigos de dois periódicos nacionais de enfermagem. Nas análises utilizamos ferramentas propostas por Michel Foucault Que possibilitaram constituir Quatro categorias: a morte silenciada e ocultada; travando uma luta contra a morte; a morte em cena: multiplicidade de facetas e a morte e os cuidados paliativos: mudança de paradigma. O estudo destaca o modo como as publicações operam na produção dos saberes sobre a morte e o morrer subjetivando as enfermeiras.

Descritores: Cuidados Paliativos; Enfermagem; Morte.

\section{ABSTRACT}

We consider looking at the death and dying as a social, historical and cultural construction. Thus, in we approach them to the Cultural Studies to know nurses' speeches on the subject. The research is periodic articles of two national ones of nursing. In the analyses we use tools proposals for Michel Foucault that they make possible to constitute four categories: the silenced and occulted death; stopping one it fights against the death; the death in scene: multiplicity of faces and the palliative death and cares: paradigm change. The study detaches the way as the publications operate in the production of knowing on the death and dying to them and subjectiving the nurses.

Descriptors: Palliative Cares; Nursing; Death.

\section{RESUMEN}

Nos proponemos mirar la muerte y el morir como una construcción social, histórica y cultural. Así, nos aproximamos a los Estudios Culturales para conocer discursos de enfermeras sobre el tema. El corpus de la investigación son artículos de dos periódicos nacionales de enfermería. En nuestros análisis utilizamos herramientas propuestas por Michel Foucault Que posibilitaran construir cuatro categorías: la muerte silenciada y ocultada; entablando una lucha contra la muerte; la muerte en escena: multiplicidad de facetas, y la muerte y los cuidados paliativos: cambio de paradigma. El estudio destaca el modo en que las publicaciones operan en la producción de los saberes sobre la muerte y el morir subjetivando a las enfermeras.

Descriptores: Cuidados paliativos; Enfermería; Muerte. 


\section{INTRODUÇÃO}

Falar sobre a morte e o morrer não é uma tarefa fácil, pois essas palavras acionam mecanismos cerebrais Que afloram nossas referências de vida. Aceitar o fato de Que nossa existência, bem como a das pessoas Que amamos, tem um "prazo de validade" desconhecido, é árduo. Esse medo do desconhecido torna a morte uma Questão difícil de ser discutida, enfrentada e pesquisada.

Qual a definição de morrer? Morrer pode ser definido como deixar de viver, falecer, acabar, cair no esQuecimento! ${ }^{(1)}$ Assim, uma forma de nos mantermos vivos após a morte é na memória daqueles Que permaneceram vivos ${ }^{(2)}$. Talvez, por isso, morrer seja sinônimo de cair no esquecimento, pois o ser humano existe pelas relações Que mantém com a sociedade. A definição de morte carrega consigo alguns problemas, pois como outras definições, é circular. Por isso, conceituar, exatamente, o Que é a morte não é possível, já Que seu significado varia de acordo com a cultura(3). A cultura forma nossas identidades a partir de arranjos discursivos, submetendo-nos a relações de poder e saber Que nos governam e constituem nossas práticas ${ }^{(4)}$.

Ao ingressar na Universidade os acadêmicos de enfermagem enfrentam suas primeiras experiências relacionadas à morte nas aulas de Anatomia, Que apesar de causarem desconforto, são pouco comentadas. Essas vivências, muitas vezes silenciadas, servem para extrair saberes dos cadáveres, tomados como objetos de estudo. Observamos Que tanto as experiências nessas disciplinas básicas Quanto àQuelas no ambiente hospitalar são discutidas com "naturalidade", pelos profissionais de saúde. Essa "naturalidade" seria uma forma de negação e banalização da morte para Que os profissionais encontrem auxílio para continuar exercendo suas atividades $^{(5)}$. Assim, trabalhar essa temática e, em especial, as redes discursivas e os saberes Que a enfermagem vem construindo às suas margens seria produtivo.

Dessa maneira, propomos realizar uma aproximação com o campo dos Estudos Culturais, especificamente, sua vertente pósestruturalista para conhecer os discursos, Que as enfermeiras têm veiculado nas publicações de enfermagem acerca da morte e do morrer. Procuramos compreender os jogos de poder desses discursos, bem como sua trama discursiva da Qual não podemos escapar. Pretendemos ressaltar alguns enunciados acerca da morte e do morrer e a forma como subjetivam essas profissionais. Entendemos que os saberes são produzidos de acordo com regimes de verdade Que obedecem a determinadas racionalidades históricas. Com isso, não temos a pretensão de desvendar "verdades" sobre a morte e o morrer, pois acreditamos Que não existe nada por detrás dos textos Que precise ser descoberto ou explicado, apenas, em alguns momentos, não temos as lentes para ver ${ }^{(6)}$. Deste modo, nosso objetivo é entender como os discursos sobre a morte e o morrer circulam, nas publicações de enfermagem, bem como a forma como essa mídia opera na formação de sentidos produzindo determinadas "verdades" Que subjetivam e objetivam as enfermeiras. Para tanto, nos apoiaremos na obra de Michel Foucault, especialmente nos seus entendimentos sobre discurso, poder, saber, sujeito e disciplina.

\section{METODOLOGIA}

Para delimitar os artigos do nosso corpus utilizamos o PeriEnf, uma ferramenta disponível na base de dados da biblioteca Wanda Horta, da Escola de Enfermagem, da Universidade de São Paulo. Os unitermos utilizados para a busca de artigos foram morte, morrer e cuidados paliativos. Optamos por fazer uma hipótese de leitura dos artigos publicados na Revista Brasileira de Enfermagem (REBEn) e na Revista Gaúcha de Enfermagem, por acreditar Que elas, dentre outras, funcionam como dispositivos Que produzem identidades e veiculam alguns dos discursos tidos como "verdadeiros" na profissão. Nosso corpus de análise foi constituído por Quarenta e Quatro artigos, sendo trinta e Quatro da REBEn e dez da Revista Gaúcha de Enfermagem, publicados no período de 1937 a 2005. A coleta e análise dos dados foram feitas a partir da leitura interessada dos textos para avaliar "aQuilo que podemos aproveitar e aquilo que podemos descartar, deixar passar ou deixar de lado"(7).

\section{RESULTADOS E DISCUSSÃO}

A leitura das publicações possibilitou a construção de Quatro categorias discursivas: a morte silenciada e ocultada (1 937-1979); travando uma luta contra a morte (1980-1989); a morte em cena: multiplicidade de facetas (1990-1999) e a morte e os cuidados paliativos: mudança de paradigma (2000-2005).

\section{A Morte Silenciada e Ocultada (1937-1979)}

Nas primeiras publicações da revista, a morte e o morrer não eram assuntos recorrentes e só passaram a integrar tal cenário após o final da Segunda Guerra Mundial. A visão social desse processo foi sendo modificada podendo ser considerado Que existe um "recalcamento" da morte, à medida Que a vida ficou mais longa e a morte tornou-se adiada.

De acordo com as publicações desta época, a enfermeira não pode se emocionar e deve desenvolver habilidades de comunicação para confortar familiares e pacientes, saber administrar analgesia, promover o conforto do moribundo e satisfazer a sede espiritual dos pacientes. Os textos têm um tom dogmático, de conotação religiosa e autoritária Que manifestam a moral e a obediência, através de expressões como: "deve", "tornar-se apta”, "dever", "fazer", "conhecer" Que não deixam dúvidas Quanto ao que deve ser feito e pretendem instaurar um modelo de enfermeira. A revista também demonstra uma preocupação com o corpo e seus cuidados, especialmente, após a morte, pois esses devem ser realizados com paciência e amor. É apontada a necessidade de entregá-lo para a família com aparência de conforto, indicando a higiene e o tamponamento dos orifícios como cuidados de enfermagem imprescindíveis. Além disso, as técnicas de preparo do corpo são apresentadas para Que as enfermeiras incorporem um jeito de fazer enfermagem e cuidar dos corpos, sejam eles vivos ou mortos.

Nessa categoria discursiva as autoras utilizam formas verbais no imperativo com o intuito de incitar as enfermeiras a desenvolver as ações desejadas, pois esses verbos manifestam ordem e apelo a concretização da ação, o Que nos possibilita observar o governamento dos corpos. Além disso, ao longo dos textos, é possível observar a influência dos preceitos de Florence Nightingale, nas referências à insalubridade do ambiente onde o moribundo se encontra, Que deve ser combatida através da incidência da luz solar, boa ventilação, iluminação, limpeza e silêncio, pois como refere Foucault a medicina urbana se organizou, primeiramente, não em 
torno dos homens, mas das $\operatorname{coisas}^{(8)}$. Os métodos de Florence, utilizavam como base a moral e o disciplinamento dos corpos das enfermeiras e objetivavam introduzir a ordem no hospital para transformá-lo num local de cura, acúmulo e transmissão de saber.

\section{Travando uma Luta Contra a Morte (1980-1989)}

Nesse período, os discursos originam-se, principalmente, das profissionais Que trabalham nos Centros de Terapia Intensiva, pois com as novas tecnologias Que invadem os hospitais a morte tornase parte da rotina das enfermeiras Que ali atuam entrando na ordem do seu discurso. Assim, acreditamos que "[...] as coisas podem ser ditas, mas não são ouvidas, não são escutadas Quando ditas fora de uma ordem. Ou tu te colocas na ordem, ou tu não és escutada"(7). Tais efeitos podem ser observados no Que Foucault chamou de ritual, Que é a imposição de regras aos indivíduos Que pretendem pronunciar determinados discursos, pois eles necessitam ser Qualificados para fazê-lo ${ }^{(9)}$. Assim, as enfermeiras, Que atuam nesse contexto, têm a aprovação dessa "sociedade de discurso" para veicular, nas páginas das revistas, seus enunciados, já Que são detentoras desse saber. Foucault entende como uma "sociedade de discurso" um grupo de indivíduos, limitado, dentre os Quais, circula um determinado tipo de discursividade ${ }^{(9)}$.

Os artigos apresentam a morte como algo natural, mas sugerem Que o controle do homem sobre a natureza tem sido maior, o Que possibilitaria o prolongamento da vida através de determinados comportamentos. Aqui podemos evidenciar a sugestão de que ao assumirmos determinadas práticas e nos disciplinarmos asseguraríamos uma vida mais longa. Assim, a morte, Que antes era associada ao processo de viver, agora está associada à possibilidade de adoecer. No que se refere à equipe de saúde, a terminalidade do ser é considerada natural, porém relacionada a sentimentos de medo, impotência, tristeza, depressão, culpa, fracasso e falha. Além disso, ela aparece como algo negado, rejeitado e silenciado. Algumas publicações apontam que os sentimentos da equipe de enfermagem em relação ao cuidado de pessoas Que estão morrendo, se refletiria na Qualidade assistencial. Nos artigos, observamos referências a preocupação das enfermeiras com o cuidado do corpo e os equipamentos como forma de ocultar a morte, já que o trabalho com pacientes Que estão morrendo é tido como desestabilizador emocional da equipe. A identificação com esses pacientes e seus familiares, as dificuldades de conversar sobre o diagnóstico e o prognóstico da doença, a insuficiência de treinamento e a falta de respaldo psicológico são, também, apontadas como fatores Que prejudicam o processo assistencial. As revistas referem como atribuições da enfermeira: a observação constante, o atendimento imediato, a individualização e humanização da assistência, a boa comunicação verbal, a assistência farmacológica e fisiológica e o conforto à família e ao moribundo. Aqui podemos constatar mais uma espécie de disciplinamento que o hospital pretende produzir nos corpos dos profissionais Que ali atuam, em especial, da enfermeira, pois essa profissional deve estar apta a desenvolver certas práticas Que permitam uma normalização de suas atividades. Para isso, ela deve obedecer a um regime disciplinar que permita um controle das suas operações e assegure uma sujeição Que a torne governável.

A morte em cena: multiplicidade de facetas (1990-1999)

Nesse período, a morte antes negada, ocultada e silenciada passa a ser objeto de estudo das enfermeiras e entra em cena assumindo um dos focos da atenção profissional.

Os profissionais de saúde continuam sendo Questionados sobre suas percepções acerca do término da vida. Aqui são ressaltados os diferentes mecanismos de defesa, como a negação e a racionalização, utilizadas pela equipe de saúde para lidar com os pacientes em fase terminal. Nos artigos publicados o preparo do corpo também é objeto de preocupação, pois os profissionais sentem-se desconfortáveis ao realizar tal prática. A sugestão de um espaço terapêutico para a equipe de enfermagem emerge como necessidade, já Que nesse local poderiam ser trabalhados sentimentos frente a perda o que aumentaria a satisfação no trabalho e a Qualidade da assistência. A temática da morte emerge, ainda, relacionada à educação sugerindo a necessidade de incluí-la nos currículos de enfermagem para Que não continue silenciada. Assim, os alunos de graduação manifestam a vontade de discutir Questões relativas ao assunto para Que o currículo, Que é voltado para a cura e para a preservação da vida, os prepare para enfrentar, também, a morte. As enfermeiras apontam Que esse conteúdo deveria ser incluído nos programas de educação em serviço o Que melhoraria a Qualidade da assistência e diminuiria a ansiedade, o medo e a dor da equipe de saúde.

Com o aumento da violência, as enfermeiras passam a preocuparse com as mortes relacionadas às causas externas, já Que tais acontecimentos seriam preveníveis e estão se tornando um problema de saúde pública. Assim, os conhecimentos epidemiológicos são incorporados a esse saber como forma de estabelecer uma relação entre mortalidade e violência. A terminalidade da vida aparece como um desafio Que ameaça os indivíduos devido a falta de explicações científicas dos acontecimentos Que a sucedem.

Nessa década, as enfermeiras discutem a transferência da morte do ambiente domiciliar, onde era um fenômeno coletivo, junto a amigos e parentes, para o contexto hospitalar, onde se torna solitária, acompanhada por estranhos, tornando-se um evento dramatizado. Entram em pauta as Questões relacionadas a "morte social", Que é o isolamento do moribundo do convívio coletivo antes do acontecimento de sua morte biológica. Quanto ao ambiente hospitalar, algumas publicações defendem a flexibilização das normas disciplinares das instituições permitindo ao moribundo Que permaneça com seus familiares até seus últimos dias.

Nos artigos das revistas, a figura do médico aparece, como alguém Que lida com a morte de forma impessoal, fria e objetiva por meio de sentimentos ilusórios de soberania no controle das situações de vida-morte, já Que esse profissional seria o detentor do poder de prolongar a vida. A figura da enfermeira emerge como a profissional Que presta cuidados com fortes sentimentos e Que deve os conter perante o paciente. É citado, também, Que essas profissionais para se afastarem da morte valorizam procedimentos técnicos em detrimento da relação interpessoal. Entendemos Que essas características atribuídas ao médico e a enfermeira carregam nos seus discursos Questões de gênero. $\mathrm{O}$ médico, representado pelo sexo masculino, emerge como um ser sem fragilidades emocionais, poderoso e com superioridade em relação ao sexo feminino, ou seja, o ser Que tem o "poder da cura" e que, portanto, desqualifica as práticas de cuidado(10). As enfermeiras, Que organizaram suas práticas baseadas nas ordens sacras, desempenham atividades tidas, na cultura, como "naturalmente" femininas tais como: cuidado e nutrição, pois essa profissional está 
associada à figura da mulher-mãe, detentora de um saber tipicamente feminino de práticas de cuidados Que se profissionaliza e estabelece relações de trabalho num universo médico-masculino ${ }^{(10,11)}$.

\section{Morte e Cuidados Paliativos: mudança de paradigma (2000- 2005)}

As publicações das enfermeiras acerca da temática, a partir dos anos dois mil, aumentam bruscamente, e em cinco anos, o número de artigos publicados é Quase igual ao das sete décadas anteriores. As novidades, nos periódicos de enfermagem, centram-se no surgimento dos cuidados paliativos, como saber científico e objeto de apropriação profissional. Assim, a morte e o morrer passam a ser vistos sob um "novo regime de discurso" Que possibilitaria pensar na chegada do fim da vida como resultante de um processo "natural"(2). Inicia-se, assim, uma modificação nos enunciados e nas formas como eles se implicam e são regidos para serem aceitos como "verdades"(8)

É nesse princípio de século, Que as autoras se ocupam mais intensamente de temáticas referentes ao deslocamento da morte do ambiente domiciliar para o hospitalar e apontam que o hospital é o local onde o indivíduo é despido de sua individualidade e identidade e onde ficam ocultados aspectos sórdidos da doença. Nas revistas, as autoras referem Que a morte nos hospitais é negada, mecanizada e investida de tecnologias o Que auxilia na ocultação das verdades sobre a doença. Assim, as atenções das publicações se voltam para uma nova modalidade de assistência: os cuidado paliativos. Estes surgem com a finalidade de incluir o moribundo permitindo Que escolha o local da sua morte. Esses cuidados proporcionariam a família e ao doente a melhor Qualidade de vida possível, um cuidado humanizado e uma sobrevida digna mantendo o doente, o menor tempo possível, longe dos seus lugares habituais e permitindo Que ele viva com autonomia a própria morte. As publicações de enfermagem ressaltam, ainda, a importância do movimento hospice, Que despertaria uma mudança de atitude frente a terminalidade da vida por meio de um serviço multiprofissional centrado na satisfação das necessidades de cuidados e conforto e na liberdade de visitas dos familiares. As enfermeiras ressaltam Que essa filosofia pretende delegar um maior poder decisório à família e ao paciente ao contrário do Que, usualmente, ocorre no ambiente hospitalar.

Os discursos produzidos acerca dos cuidados paliativos têm a pretensão de modificar as relações de poder envoltas nos cuidados ao paciente fora de possibilidades terapêuticas. Assim, o paciente moribundo, antes ignorado pelo saber médico e suas instituições, torna-se objeto de estudo e contribui para o surgimento de um outro saber, Que busca a humanização do processo de morrer se contrapondo as tecnologias da medicina moderna ${ }^{(12)}$. Os cuidados paliativos podem ser vistos como um saber Que vem tentando tornarse científico o Que permite estabelecer certas práticas e desQualificar outras. Tal ruptura não trata de libertar os sujeitos da morte silenciada e ocultada, mas de colocá-la em uma nova ordem de discurso submetida a outros dispositivos de poder e $\operatorname{saber}^{(13)}$.

\section{CONSIDERAÇÕES FINAIS}

Notamos Que o saber sobre a morte, objeto de múltiplas discursividades, é permeado por dúvidas Que a ciência moderna não consegue esclarecer já Que observamos uma busca por "verdades", e não encontramos autoras Que discursassem sobre uma "morte científica", ou seja, um discurso Que carregue consigo as verdades tão comuns na ciência moderna. Nesse sentido, não Queremos criticar a forma como esses saberes e poderes se articulam nem como nos tornamos sujeitos de tais discursos, já Que não nos colocamos fora dessas práticas e não estamos isentas de suas ações. Aqui, propomos ensaiar uma das possíveis formas de entender como diferentes dispositivos se articulam num funcionamento social constituindo aQuilo Que somos, valorizando determinadas práticas e desqualificando outras.

Os humanos sempre desejaram encontrar uma explicação sobre porque se morre ${ }^{(2)}$. Nessa perspectiva, a vontade de verdade, um procedimento de controle e delimitação do discurso, atravessa a civilização fazendo com Que, cada um de nós, deseje ser o detentor de um discurso verdadeiro Que tenha o aval da sociedade e da comunidade cientifica para Que possa circular e carregar determinados poderes. Tal discurso guarda relação direta com a vontade de saber. Assim, vontade de saber e vontade de verdade (re)surgem e se (re)formulam, ao longo do tempo, de acordo com os modos pelos Quais o saber é distribuído na sociedade e com os tipos de verdades Que são valorizadas ${ }^{(9)}$.

Como Foucault, pensamos Que resgatar esses discursos nos auxilia a entender como enfermeiras e pacientes vão sendo constituídos e subjetivados tornando-se objetos-objetivo nessa rede de saber e poder Que tem efeitos de verdade na assistência de enfermagem $^{(8)}$.

\section{REFERÊNCIAS}

1. PRIBERAN. Morrer. Dicionário Priberan da Língua Portuguesa. Lisboa: Universal; 2006. [citado 02 out 2006]. Disponível em: URL: http://www.priberam.pt/

2. Elias N. A solidão dos moribundos: seguido de envelhecer e morrer. Rio de Janeiro: Jorge Zahar; 2001.

3. Valls ALM. Repensando a vida e a morte do ponto de vista filosófico. In: Goldim IR. Bioética e ética na ciência. Porto Alegre: UFRGS; 2002.

4. Hall S. A centralidade da cultura: notas sobre as revoluções do nosso tempo. Educ Real 1997; 22(2): 1 5-46.
5. Martins EL, Alves RN, GODOY SAF. Reações e sentimentos do profissional de enfermagem diante da morte. Rev Bras Enferm 1999; 52(1): 105-17.

6. Kellner D. A cultura da mídia: estudos culturais: identidade e política entre o moderno e o pós-moderno. Bauru: EDUSC; 2001.

7. Fischer RMB, Veiga-Neto A. Foucault, um diálogo. Educ Real 2004; 29(1): 7-25.

8. Foucault M. Microfísica do Poder. $2 \mathrm{I}^{\mathrm{a}}$ ed. Rio de Janeiro: Graal; 2005. 
9. Foucault M. A ordem do discurso: aula inaugural no Collège de France, pronunciada em 2 de dezembro de 1970. 13a ed. São Paulo: Edições Loyola; 2006.

10. Lopes MIM, Leal SMC. A feminização persistente na Qualificação profissional da enfermagem brasileira. Cad Pagu 2005; (24): 105-25.

11. Kruse MHL. Os Poderes dos corpos frios: das coisas Que se ensinam às enfermeiras. Brasília: ABEn; 2004.
12. Menezes RA. Em busca da "boa morte": uma investigação sócio-antropológica sobre cuidados paliativos [tese]. Rio de Janeiro (RI): Instituto de Medicina social, Universidade do Estado do Rio de Janeiro; 2004.

13. Carrara S. Prefácio. In: Menezes RA. Em busca da boa morte: antropologia dos cuidados paliativos. Rio de Ianeiro: Garamond/FIOCRUZ; 2004. p. I I-3. 